\title{
Molecular Characterization of Cultivated Pawpaw (Asimina triloba) Using RAPD Markers
}

\author{
Hongwen Huang ${ }^{1}$ \\ Wuhan Institute of Botany, The Chinese Academy of Sciences, Wuhan, Hubei 430074, P.R. China
}

\author{
Desmond R. Layne ${ }^{2}$ \\ Department of Horticulture, Clemson University, Clemson, SC 29634-0375
}

Thomas L. Kubisiak ${ }^{3}$

U.S. Department of Agriculture Forest Service, Southern Research Station, Southern Institute of Forest

Genetics, Saucier, MS 39574

Additional index words. DNA fingerprinting, cultivar identification, genetic relatedness, cluster analysis

\begin{abstract}
Aвstract. Thirty-four extant pawpaw [Asimina triloba (L.) Dunal] cultivars and advanced selections representing a large portion of the gene pool of cultivated pawpaws were investigated using 71 randomly amplified polymorphic DNA (RAPD) markers to establish genetic identities and evaluate genetic relatedness. All 34 cultivated pawpaws were uniquely identified by as few as 14 loci of eight primers. Genetic diversity of the existing gene pool of cultivated pawpaws, as estimated by Nei's gene diversity (He), was similar to that of wild pawpaw populations. The genetic relatedness among the cultivated pawpaws examined by UPGMA cluster analysis separated 34 cultivars and selections into two distinct clusters, a cluster of PPF (The PawPaw Foundation) selections and a cluster including a majority of the extant cultivars selected from the wild and their derived selections. The results are in general agreement with the known selection history and pedigree information available. The consensus fingerprint profile using the genetically defined RAPD markers is a useful and reliable method for establishing the genetic identities of the pawpaw cultivars and advanced selections. This also proved to be an improved discriminating tool over isozyme markers for the assessment of genetic diversity and relatedness. RAPD profiling of data presented in this study provides a useful reference for germplasm curators engaged in making decisions of sampling strategies, germplasm management and for breeders deciding which parents to select for future breeding efforts.
\end{abstract}

The North American pawpaw [Asimina triloba (L.) Dunal] is native to 25 states of the eastern United States ranging from northern Florida to southern Ontario (Canada) and as far west as Nebraska, and it is the largest native tree fruit (Darrow, 1975; Kral, 1960; White, 1906). Pawpaw is well suited to most tobacco growing regions of the United States and it is being investigated as one potential high-value replacement crop (Layne, 1996; Pomper et al., 1999). Its delicious and custard-like fruit is an excellent food source that exceeds many common fruits in vitamins, minerals, amino acids and food energy values (Jones and Layne, 1997; Peterson, et al., 1982). Pawpaw has tremendous potential as a landscape plant due to its attractive form and foliage and it is being used in butterfly gardens since it is the exclusive larval host plant for the zebra swallowtail butterfly (Eurytides marcellus Cramer) (Damman, 1986). Natural compounds (annonaceous acetogenins) in leaf, bark, and twig tissue possess

Received for publication 18 Apr. 2002. Accepted for publication 3 Oct. 2002. This research was supported by U.S. Dept. Agr. 1890 Institution Research Capacity Building Grant 92-38814-7485 awarded to Kentucky State University. We would like to thank R. Neal Peterson, founder of The PawPaw Foundation, for plant material and for critical comments on the manuscript and also Glen N. Johnson and Kristel B. Davis for skilled technical assistance with DNA extraction and PCR amplification.

${ }^{1}$ Professor of plant genetics and breeding, Wuhan Institute of Botany. Former Coinvestigator of horticulture, Kentucky State University.

${ }^{2}$ Corresponding author. Former principal investigator of horticulture and curator, USDA Clonal Germplasm Repository for Asimina sp., Kentucky State University. Currently assistant professor of pomology and extension tree fruit specialist, Dept. of Horticulture, Box 340375, Clemson University, Clemson, SC 296340375; e-maildlayne@clemson.edu.

${ }^{3}$ Research plant geneticist, U.S. Dept. Agr. Forest Service, Southern Research Station, Southern Institute of Forest Genetics, 23332 Highway 67, Saucier, MS 39574. insecticidal and anticancer properties (Johnson, et al., 1996; McLaughlin, 1997). Harvesting the leaves and twigs for extraction of these compounds may also present a lucrative opportunity for small farmers in the future (Pomper et al., 1999).

The cultivated pawpaw is represented by more than 40 clonal cultivars and selections that are currently available in commercial nurseries and germplasm repositories (Jones et al., 1998; Layne, 1996, 1997). Most of these were selected from the wild or as openpollinated seedlings from historical collections (Peterson, 1991). The history of domestication and cultivation of pawpaw dates back to 1541 when native Indians were observed growing pawpaw by early Spanish explorers in the Mississippi Valley (Pickering, 1879). However, organized breeding efforts to select superior genotypes were not initiated in the United States until the early part of the 20th century (Flory, 1958; Popenoe, 1917; Zimmerman, 1941). Unfortunately, of 56 selected and named cultivars from these early breeding efforts, most no longer exist today since collections were neglected or abandoned and propagation and cultivation was not continued. The currently available pawpaw cultivars and new selections since 1960 are primarily due to the collection efforts of R. Neal Peterson (founder, The PawPaw Foundation) and many other pawpaw enthusiasts (Peterson, 1986, 1991). Another pivotal factor that reversed the trend towards genetic erosion of cultivated pawpaw was the development of a comprehensive research program at Kentucky State University (KSU) established in 1990 to develop pawpaw as a new commercial fruit tree crop for Kentucky and the United States (Layne, 1996). This effort was furthered by the U.S. Dept. of Agriculture approval and federal funding in 1994 to establish KSU as the National Clonal Germplasm Repository for Asimina spp. and funding to collect germplasm from pawpaw's native 
range to expand the diversity of germplasm contained in the collection (Layne, 1996). Due to the resurgence of interest in the commercial development of pawpaw as a new fruit crop, it has become necessary to precisely characterize the genetic diversity that exists in cultivars, advanced selections and native populations. This is one step toward providing accurate genetic information for future breeding and germplasm collection efforts (Huang, et al., 2000; Layne, 1996).

Similar to most newly domesticated perennials, especially outcrossing fruit tree species with poorly documented selection history and missing records, cultivar identification of pawpaw based on morphological differences alone has proven to be difficult. Twenty-seven cultivars or selections described in the latest edition of Brooks and Olmo's Register of Fruit \& Nut Varieties were listed with only brief information on fruit weight and skin and flesh color because little information has been documented (Layne, 1997). Efforts need to be made to note morphological differences so that commercial nurseries can maintain strong quality control of cultivar identities through the clonal propagation process. Until recently, isozymes have been used to identify pawpaw cultivars and characterize their genetic diversity (Huang et al., 1997, 1998). However, the paucity of isozyme loci has somewhat limited the effectiveness of discriminating all cultivars and the ability to thoroughly assess the genetic

Table 1. Pawpaw cultivars and advanced selections evaluated in this study. ${ }^{\mathrm{z}}$

\begin{tabular}{|c|c|c|c|}
\hline Cultivar or selection & Breeding pedigree and Origin & Selected year & Selector \\
\hline 1. $\mathrm{PPF}^{\mathrm{y}}$ 1-7 (Keedysville) & Open-pollinated seedling of $\mathrm{BEF}^{\mathrm{x}}-30$ & 1991 & R.N. Peterson \\
\hline 2. PPF 1-7 (Wye) & Open-pollinated seedling of 'Overleese' & 1994 & R.N. Peterson \\
\hline 3. PPF $1-23$ & Open-pollinated seedling of 'Taytwo' & 1991 & R.N. Peterson \\
\hline 4. PPF $1-68$ & Open-pollinated seedling of 'Overleese' & 1994 & R.N. Peterson \\
\hline 5. PPF 2-10 & Open-pollinated seedling of BEF-30 & 1994 & R.N. Peterson \\
\hline 6. PPF 2-49 & Open-pollinated seedling of $\mathrm{GAZ}^{\mathrm{w}}-\mathrm{VA}$ & $?$ & R.N. Peterson \\
\hline 7. PPF 2-54 & Open-pollinated seedling of GAZ-VA & 1991 & R.N. Peterson \\
\hline 8. PPF 3-11 & Open-pollinated seedling of BEF-33 & 1994 & R.N. Peterson \\
\hline 9. PPF 3-21 & Open-pollinated seedling of BEF-43 & 1994 & R.N. Peterson \\
\hline 10. PPF 4-2 & Open-pollinated seedling of BEF-53 & 1994 & R.N. Peterson \\
\hline 11. PPF 5-5 & Open-pollinated seedling of BEF-54 & 1994 & R.N. Peterson \\
\hline 12. PPF 7-90 & Open-pollinated seedling of $\mathrm{RS}^{\mathrm{v}}-2$ & 1994 & R.N. Peterson \\
\hline 13. PPF $8-20$ & Open-pollinated seedling of 'Sunflower' & 1994 & R.N. Peterson \\
\hline 14. PPF 8-58 & Open-pollinated seedling of BEF-30 & 1991 & R.N. Peterson \\
\hline 15. PPF 9-47 & Open-pollinated seedling of BEF-49 & 1991 & R.N. Peterson \\
\hline 16. PPF 9-58-1 & Open-pollinated seedling of BEF-50 & 1991 & R.N. Peterson \\
\hline 17. PPF 9-58-2 & Open-pollinated seedling of BEF-50 & 1991 & R.N. Peterson \\
\hline 18. PPF 10-35 & Open-pollinated seedling of BEF-49 & 1991 & R.N. Peterson \\
\hline 19. PPF 11-5 & Open-pollinated seedling of BEF-53 & 1991 & R.N. Peterson \\
\hline 20. PPF 11-13 (KSU repository) & Open-pollinated seedling of BEF-53 & 1991 & R.N. Peterson \\
\hline 21. PPF 11-13 (PPF) & Open-pollinated seedling of BEF-53 & 1991 & R.N. Peterson \\
\hline 22. Middletown & Wild seedling from Middletown, Ohio & 1915 & E.J. Downing \\
\hline 23. Mitchell & Wild seedling from Iuka, Ill. & 1979 & J.W. Hickman \\
\hline 24. NC-1 & 'Davis' x 'Overleese' & 1976 & R.D. Campbell \\
\hline 25. Overleese & Cultivated seedling (open-pollinated) from Rushville, Ind. & 1950 & W.B. Ward \\
\hline 26. PA-Golden & Wild seedling from eastern Pennsylvania & $?$ & J. Gordon \\
\hline 27. Prolific & Cultivated seedling (open-pollinated) from Bellevue, Mich. & $\approx 1985$ & C. Davis \\
\hline 28. Rebecca’s Gold & Open-pollinated seed from Corwin Davis of Bellevue, Mich. & 1974 & J. M. Riley \\
\hline 29. SAA-Zimmerman-1(PPF) & Open-pollinated seedling of 'Zimmerman' & 1982 & J. Gordon \\
\hline 30. SAA-Zimmerman-2(PPF) & Open-pollinated seedling of 'Zimmerman' & 1982 & J. Gordon \\
\hline 31. Sunflower & Wild seedling from Chanute, Kans. & 1970 & M. Gibson \\
\hline 32. Sweet Alice & Wild seedling from Wirt Co., W.Va. & 1934 & H. Jacobs \\
\hline 33. Taylor & Wild seedling from Eaton Rapids, Mich. & 1968 & C. Davis \\
\hline 34. Taytwo & Wild seedling from Eaton Rapids, Mich. & 1968 & C. Davis \\
\hline 35. Wells (original tree) & Cultivated seedling (open-pollinated) from Salem, Ind. & 1990 & D. Wells \\
\hline 36. Wells (PPF) & Cultivated seedling (open-pollinated) from Salem, Ind. & 1990 & D. Wells \\
\hline 37. Wilson & Wild seedling from Harlan Co., Ky. & 1985 & J.V. Creech \\
\hline
\end{tabular}

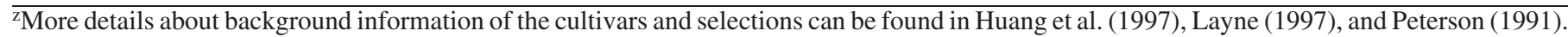
yPPF = PawPaw Foundation orchards; numerous wild selections from the remnant collections of Allard, Blandy, Buckman, Hershey, Schlaanstine and Zimmerman, plus some from truly wild trees and some from named cultivars; assembled by R. Neal Peterson and Harry J. Swartz at the experiment stations of the University of Maryland, Keedysville and Queenstown, Md.

${ }^{\mathrm{x}} \mathrm{BEF}$ = Blandy Experimental Farm collection; numerous wild selections plus a portion of Zimmerman's collection, donated posthumously; assembled by Orland E. White and staff of the Blandy Experimental Farm, Boyce, Va., from 1926 to 1955.

${ }^{\mathrm{w}} \mathrm{GAZ}=$ George A. Zimmerman collection; containing most, if not all, of the named cultivars of the time, plus numerous wild selections and interspecific hybrids; assembled by George A. Zimmerman of Linglestown, Pa., from $\approx 1920$ to 1940 .

vRS = Ray Schlaanstine collection; material descending from Zimmerman's collection via John Hershey; assembled by Ray Schlaanstine of West Chester, Pa., date uncertain, (circa 1960?). 
diversity of both cultivated and wild pawpaws (Huang et al., 1997, 1998). In our previous cultivar study (Huang et al., 1997), only nine polymorphic loci from 23 enzymes were found to be informative for cultivar identification. As a result, eight of the 32 cultivars or advanced selections were not uniquely identified. The genetic relationship among existing cultivars and advanced selections as evaluated by isozyme markers resulted in less-thansatisfactory information regarding the known genetic background, and little useful information for germplasm custodians and breeders (Huang et al., 1997). This disappointing result revealed a need for an improved means for pawpaw cultivar identification. In the present study, we used randomly amplified polymorphic DNA (RAPD) markers with the goals of 1) fingerprinting pawpaw cultivars and selections, and 2) assessing the genetic diversity and relatedness of cultivated pawpaws and advanced selections.

\section{Materials and Methods}

Plant materials. Stem cuttings of 34 clonally propagated cultivars and advanced selections were collected in Spring 1997 after their chilling requirement had been received. Cuttings came from the the USDA National Clonal Germplasm Repository for Asimina species at KSU, Frankfort, Kentucky and R. Neal Peterson of The PawPaw Foundation (PPF). Cuttings were immediately placed in separate labeled bags and shipped overnight to the USDA Forest Service, Southern Institute of Forest Genetics, Saucier, Mississippi. The samples represented many of the commercially available pawpaw cultivars and advanced selections currently available (Peterson, 1991) and included all of the entries in the pawpaw regional variety trial (Pomper et al., 1999). A total of 37 clones were sampled (Table 1). In some cases, two samples of the same clone or cultivar thought to be identical were evaluated to determine whether they were genetically identical. Two samples of 'Wells' were evaluated. One sample was from the original 'Wells' tree and the other from PPF as used in the regional variety trial. The latter was first propagated from the original tree by Northwoods nursery (Molalla, Ore.) and then supplied to R. Neal Peterson of PPF for the trial. Two samples of PPF 9-58 (designated PPF 9-58-1 and PPF 9-58-2, respectively) were provided by PPF and were thought to be half siblings. Also two samples of SAA-Zimmerman were provided by PPF (denoted SAA-Zimmerman-1 and SAA-Zimmerman-2) and were thought to be half siblings. All stem cuttings were placed in water in a greenhouse and leaf tissue was collected as new shoots emerged.

DNA EXTRACTION. Total nucleic acids were isolated from $\approx 2$ g of leaf tissue using a modification of the cetyltrimethylammonium bromide (CTAB)-based procedure outlined in Wagner et al. (1987). The RNA component of these individual extracts was removed by incubation in the presence of RNase A as described in Ausubel et al. (1987). Oligonucleotide 10-base primers were obtained from Operon Technologies Inc. (Alameda, Calif.).

RAPD AMPLIFICATION. DNA amplification was based on the protocol reported by Williams et al. (1990). The reaction consisted of the following in $24 \mu \mathrm{L}$ total volume: $6.25 \mathrm{ng}$ template DNA, $1 \mu \mathrm{L}$ primer DNA (5 $\mu \mathrm{m}$ stock), $3.6 \mu \mathrm{L}$ dNTPs (1 mM stock), $2.4 \mu \mathrm{L}$ 10X Taq DNA polymerase reaction buffer $(500 \mathrm{~mm}$ $\mathrm{KCl}, 100 \mathrm{~mm}$ Tris- $\mathrm{HCl}, 1.0 \%$ Triton $\mathrm{X}-100,15 \mathrm{~mm} \mathrm{MgCl}_{2}$ ), and 0.8 U Taq DNA polymerase. Reactions were loaded in flexible microtitre plates and overlaid with $25 \mu \mathrm{L}$ of mineral oil. Microtitre plates were placed in preheated $\left(85^{\circ} \mathrm{C}\right) \mathrm{MJ}$ Research PTC-100 programmable temperature cyclers (Watertown, Mass.) and cov- ered with mylar film. The DNA samples were amplified using the following thermal profile: $5 \mathrm{~s}$ at $95^{\circ} \mathrm{C} ; 1 \mathrm{~min} 55 \mathrm{~s}$ at $92^{\circ} \mathrm{C}$; followed by 45 cycles of $5 \mathrm{~s}$ at $95^{\circ} \mathrm{C}, 55 \mathrm{~s}$ at $92^{\circ} \mathrm{C}, 1 \mathrm{~min}$ at $35^{\circ} \mathrm{C}$, and $2 \mathrm{~min}$ at $72{ }^{\circ} \mathrm{C}$; followed by $7 \mathrm{~min}$ at $72^{\circ} \mathrm{C}$. The reactions ended with an indefinite hold at $4{ }^{\circ} \mathrm{C}$.

ELECTROPHORESIS. Amplification products were electrophoresed in 2\% agarose gels and TAE buffer (40 mM Tris base, $20 \mathrm{~mm}$ sodium acetate, $2.0 \mathrm{~mm}$ EDTA, glacial acetic acid to $\mathrm{pH} 7.2$ ) for $\approx 3.5 \mathrm{~h}$ at $3 \mathrm{~V} \cdot \mathrm{cm}^{-1}(150 \mathrm{~V})$. A total of $3.0 \mu \mathrm{L}$ loading buffer $(10 \times$ TAE, $50 \%$ glycerol, and $0.25 \%$ bromophenol blue) was added to each reaction before electrophoresis. After electrophoresis, gels were stained with ethidium bromide $\left(0.4 \mu \mathrm{g} \cdot \mathrm{mL}^{-1}\right)$ for $45 \mathrm{~min}$, washed in distilled water for $1.0 \mathrm{~h}$, and photographed under ultraviolet light using a Polaroid MP-4 camera and Polaroid 667 instant film (Cambridge, Mass.).

Marker SCORING AND DATA ANALYSIS. One hundred RAPD primers (Operon Technologies, kits A-E) were used for initial screening against the five cultivars with the highest heterozygosity based on our previous isozyme profiles (Huang et al., 1997) to identify polymorphic RAPD markers. Each sample was amplified at least two times to verify reproducibility. Thirty-seven primers that amplified a total of 71 reproducible polymorphic bands were then selected to characterize the remainder of the cultivars and advanced selections. Eleven RAPD markers were previously verified as single Mendelian loci in interspecific crossed families (Huang et al., 2000). The RAPD markers were designated by the manufacturer primer code corresponding to the 10-base primer responsible for their amplification, followed by a four digit number indicating the product size in base pairs (Table 2). RAPD phenotypes were scored as 1 (band present) or 0 (band absent), respectively, resulting in a $37 \times 71$ matrix. Dice (1945) coefficients [which is equivalent to Nei and Li (1979) genetic identity] were calculated for all possible pairwise combinations of pawpaw cultivars. As genetic diversity estimators, Nei's (1973) gene diversity (He) and Shannon and Weaver's (1949) index (I) were also calculated. A dendrogram was constructed based on the matrix of the Dice coefficients by unweighted pairgroup mean analysis (UPGMA) using the software NTSYS-pc v.1.8 (Exeter Software, Setauket, N.Y.).

\section{Results and Discussion}

IDENTITY AND DIVERSITY. Thirty-four pawpaw cultivars and advanced selections were uniquely identified by as few as 14 loci of eight primers (Table 2). In comparison to a $75 \%$ partial discrimination by 18 isozyme loci of 23 enzymes (Huang, et al., 1997), the application of genetically defined RAPD markers resulted in a substantial improvement in discriminatory effectiveness. The profile of the 71 RAPD markers for each cultivar listed in Table 2 furnishes the first benchmark of cultivated pawpaw fingerprints informative for germplasm repository management and nurseries engaged in commercial pawpaw propagation.

One cultivar ('Wells') and one selection (PPF 11-13) were sampled from different sources and were verified by the RAPD markers and genetic identity analysis (Table 3). Two independent entries of PPF 11-13 showed an identical RAPD profile. The genetic identity, as measured Dice's coefficient, between the two entries was 0.999 and confirmed that the clone at the KSU germplasm repository is identical to the clone from The PawPaw Foundation (Tables 2 and 3). In the case of 'Wells' (a cultivar selected in 1990 by D. Wells, from the wild, Salem, Indiana; Layne, 1997), a minor genetic variation was detected between the 
Table 2. RAPD markers scored for 37 pawpaw cultivars or selections.

\begin{tabular}{|c|c|c|c|c|c|c|c|c|c|c|c|c|c|c|c|c|c|c|c|}
\hline \multirow[b]{2}{*}{ Marker } & \multicolumn{17}{|c|}{ Cultivar and advanced selection ${ }^{\mathrm{z}}$} & & \\
\hline & 1 & 2 & 3 & 4 & 5 & 6 & 7 & 8 & 9 & 10 & 11 & 12 & 13 & 14 & 15 & 16 & 17 & 18 & 19 \\
\hline$\overline{\mathrm{A} 01-1090}$ & 0 & 0 & 0 & 0 & 1 & 1 & 0 & 1 & 1 & 1 & 1 & 0 & 1 & 1 & --- & 1 & 1 & 1 & 0 \\
\hline A01-0950 & 0 & 1 & 0 & 1 & 1 & 1 & 0 & 1 & 1 & 1 & 0 & 1 & 1 & 0 & --- & 1 & 1 & 1 & 1 \\
\hline A07-1600 & 1 & 0 & 0 & 1 & 0 & 1 & 0 & 0 & 0 & 0 & 0 & 0 & 0 & 0 & 0 & 0 & 1 & 0 & 0 \\
\hline A07-0600 & 0 & 1 & 1 & 0 & 0 & 0 & 1 & 0 & 0 & 0 & 0 & 0 & 0 & 1 & 0 & 1 & 0 & 0 & 1 \\
\hline A10-1075 & 0 & 0 & 1 & 0 & 1 & 0 & 0 & 1 & 0 & 1 & 0 & 1 & 0 & 1 & --- & 0 & 0 & 1 & 0 \\
\hline A10-0775 & 0 & 1 & 1 & 0 & 1 & 0 & 0 & 1 & 1 & 1 & 1 & 0 & 0 & 0 & --- & 0 & 0 & 1 & 1 \\
\hline A10-0700 & 1 & 0 & 0 & 1 & 0 & 1 & 1 & 0 & 0 & 0 & 0 & 0 & 1 & 0 & --- & 1 & 1 & 0 & 0 \\
\hline A11-0850 & 0 & 0 & 1 & 0 & 0 & 1 & 0 & 0 & 0 & 0 & 0 & 1 & 0 & 0 & 0 & 0 & 0 & 0 & 0 \\
\hline A11-0600 & 0 & 0 & 0 & 0 & 0 & 0 & 0 & 0 & 0 & 0 & 0 & 0 & 0 & 0 & 0 & 0 & 0 & 0 & 1 \\
\hline A11-0425 & 0 & 0 & 0 & 0 & 0 & 0 & 0 & 1 & 0 & 0 & 0 & 0 & 0 & 0 & 0 & 0 & 0 & 0 & 0 \\
\hline A12-0550 & 0 & 0 & 0 & 0 & 0 & 0 & 0 & 0 & 0 & 0 & 1 & 0 & 0 & 0 & 0 & 1 & 0 & 1 & 0 \\
\hline A16-1400 & 0 & 1 & 1 & 0 & 1 & 0 & 0 & 0 & 0 & 0 & 1 & 1 & 0 & 0 & 1 & 1 & 1 & 0 & 1 \\
\hline B04-0600 & 1 & 1 & 1 & 1 & 1 & 1 & 1 & 1 & 1 & 1 & 1 & 0 & 1 & 0 & --- & 1 & 1 & 1 & 1 \\
\hline B05-0675 & 0 & 0 & --- & 0 & 0 & 1 & 0 & 0 & 0 & 0 & --- & 0 & 0 & 0 & --- & 0 & 1 & 0 & 0 \\
\hline В07-1200 & 1 & 0 & 0 & 0 & 0 & 0 & 1 & 1 & 1 & 0 & 0 & 0 & 0 & 0 & 0 & 1 & 1 & 0 & 1 \\
\hline B07-0550 & 1 & 1 & 1 & 1 & 0 & 0 & 1 & 0 & 0 & 0 & 0 & 0 & 0 & 1 & 0 & 0 & 0 & 0 & 1 \\
\hline B08-0900 & 0 & 1 & 0 & 0 & 0 & 1 & 0 & 0 & 1 & 0 & 1 & 1 & 0 & 1 & 1 & 0 & 0 & 0 & 0 \\
\hline В09-0900 & 0 & 1 & 0 & 0 & 0 & 1 & 0 & 0 & 1 & 0 & 1 & 1 & 0 & 1 & 1 & 0 & 0 & 0 & 0 \\
\hline B10-1775 & 1 & 0 & 0 & 1 & 0 & 0 & 0 & 0 & 0 & 0 & 0 & 0 & 1 & 0 & 0 & 0 & 0 & 0 & 0 \\
\hline B10-1200 & 0 & 0 & 0 & 0 & 0 & 0 & 1 & 0 & 0 & 0 & 0 & 0 & 0 & 0 & 0 & 1 & 0 & 1 & 0 \\
\hline B10-0950 & 1 & 1 & 0 & 1 & 1 & 1 & 1 & 0 & 0 & 1 & 1 & 1 & 1 & 0 & 0 & 0 & 1 & 0 & 1 \\
\hline B10-0900 & 0 & 1 & 0 & 0 & 1 & 0 & 0 & 0 & 0 & 1 & 0 & 0 & 0 & 0 & 1 & 0 & 0 & 0 & 0 \\
\hline B11-0525 & 1 & 0 & 0 & 1 & 0 & 0 & 0 & 0 & 0 & 0 & 0 & 0 & 0 & 0 & 0 & 0 & 0 & 0 & 0 \\
\hline B15-1600 & 1 & 1 & 1 & 1 & 0 & 1 & 1 & --- & 0 & 0 & 1 & 0 & 1 & 1 & --- & 1 & 1 & 0 & 1 \\
\hline $\mathrm{C} 02-1600$ & 0 & 1 & 1 & 0 & 1 & 1 & 1 & 1 & 1 & 1 & 1 & 1 & 1 & 1 & 1 & 1 & 1 & 1 & 1 \\
\hline C02-0650 & 1 & 0 & 1 & 1 & 0 & 1 & 1 & 0 & 0 & 1 & 0 & 1 & 1 & 0 & 1 & 1 & 1 & 0 & 0 \\
\hline C04-1300 & 1 & 0 & 0 & 0 & 0 & 0 & 0 & 0 & 1 & 1 & 1 & 1 & 1 & 0 & 0 & 1 & 1 & 0 & 1 \\
\hline C04-0325 & 1 & 1 & 0 & 1 & 1 & 0 & 1 & --- & --- & 1 & 1 & 0 & 0 & 0 & 0 & 0 & 0 & 1 & 1 \\
\hline C04-1675 & 0 & 0 & 1 & 0 & 0 & 0 & 0 & 0 & 0 & 0 & 0 & 0 & 1 & 0 & 0 & 0 & 0 & 0 & 0 \\
\hline C04-1175 & 0 & 0 & 0 & 0 & 0 & 0 & 0 & 1 & 0 & 0 & 0 & 0 & 0 & 0 & 0 & 0 & 0 & 0 & 0 \\
\hline C07-0500 & --- & 0 & 0 & 0 & 0 & 0 & 0 & 0 & 0 & 0 & 0 & 0 & 0 & 0 & 1 & 0 & 0 & --- & 0 \\
\hline C07-0425 & --- & 0 & 0 & 0 & 0 & 0 & 0 & 1 & 0 & 0 & 0 & 0 & 0 & 0 & 0 & 0 & 0 & --- & 0 \\
\hline C08-0425 & 0 & 0 & 1 & 1 & 0 & 0 & 0 & 0 & 0 & 0 & 0 & 1 & 1 & 0 & 0 & 0 & 0 & 0 & 0 \\
\hline C09-1000 & 1 & 1 & --- & 1 & 1 & 1 & 0 & 1 & 1 & 1 & 1 & 1 & 1 & 0 & 1 & 1 & 1 & 1 & 1 \\
\hline C10-0950 & --- & 0 & 0 & 1 & 0 & 0 & 1 & 1 & 0 & 0 & 0 & 0 & 1 & --- & --- & 1 & 1 & 1 & 1 \\
\hline C11-1550 & 0 & 0 & 0 & 0 & 0 & 0 & 0 & 0 & 0 & 0 & 0 & 0 & 0 & 0 & 0 & 0 & 0 & 0 & 0 \\
\hline C13-1500 & 0 & 0 & 0 & 0 & 0 & 0 & 0 & 0 & 0 & 0 & 0 & 0 & 0 & --- & 0 & 0 & 0 & 0 & 0 \\
\hline C13-1300 & 0 & 0 & 0 & 0 & 0 & 0 & 0 & 1 & 0 & 0 & 0 & 0 & 0 & 0 & 0 & 0 & 0 & 0 & 0 \\
\hline C15-1050 & 1 & 1 & 1 & 1 & 0 & 1 & 1 & 0 & 0 & 0 & 1 & 0 & 1 & 1 & 0 & 1 & 1 & 0 & 1 \\
\hline C15-0650 & 1 & 1 & 1 & 0 & 1 & 1 & 1 & 0 & 1 & 1 & 1 & 1 & 0 & 1 & 1 & 1 & 1 & 1 & 1 \\
\hline C20-0900 & 1 & 1 & 1 & 1 & 1 & 1 & --- & 1 & 1 & 1 & 1 & 1 & 1 & 1 & 1 & 1 & 1 & 1 & 1 \\
\hline C20-1150 & 1 & 1 & 1 & 1 & 0 & 1 & --- & 0 & 0 & 0 & 1 & 0 & 0 & 1 & 0 & 0 & 1 & 0 & 1 \\
\hline C20-0600 & 0 & 0 & 0 & 0 & 0 & 1 & --- & 0 & 1 & 0 & 0 & 1 & 1 & 1 & 0 & 1 & 1 & 0 & 0 \\
\hline D04-0835 & 0 & 0 & 0 & 0 & 1 & 1 & --- & 0 & 0 & 1 & 1 & 0 & 0 & 0 & 0 & 0 & 0 & 0 & 0 \\
\hline D05-1250 & 0 & 1 & 1 & 0 & 1 & 1 & 1 & 1 & 1 & 1 & 1 & 1 & 0 & 1 & 1 & 1 & 1 & 1 & 1 \\
\hline D05-0500 & 0 & 1 & 1 & 1 & 1 & 1 & 1 & 0 & 1 & 1 & 1 & 0 & 0 & 0 & 1 & 0 & 0 & 0 & 1 \\
\hline D05-0450 & 0 & 0 & 0 & 0 & 0 & 0 & 0 & 0 & 0 & 0 & 0 & 0 & 0 & 0 & 0 & 0 & 0 & 0 & 0 \\
\hline D05-0600 & 1 & 1 & 1 & 1 & 1 & 1 & 1 & 1 & 1 & 1 & 1 & 1 & 1 & 1 & 1 & 1 & 1 & 1 & 1 \\
\hline D05-0575 & 0 & 0 & 0 & 0 & 0 & 0 & 0 & 0 & 0 & 0 & 0 & 0 & 0 & 0 & 0 & 0 & 0 & 0 & 0 \\
\hline D15-0550 & 0 & 0 & 0 & 0 & 0 & 0 & 0 & 0 & 0 & 0 & 0 & 0 & 0 & 0 & 0 & 1 & 0 & 1 & 0 \\
\hline D15-0425 & 0 & 0 & 0 & 0 & 0 & 0 & 0 & 0 & 0 & 0 & 0 & 0 & 0 & 0 & 0 & 0 & 0 & 0 & 0 \\
\hline D16-1000 & 0 & 1 & 1 & 0 & 1 & 0 & 1 & 0 & 0 & 1 & 1 & 1 & 0 & 1 & 0 & 0 & 0 & 0 & 1 \\
\hline D16-0525 & 0 & 0 & 0 & 0 & 0 & 0 & 0 & 0 & 0 & 0 & 0 & 0 & 0 & 0 & 0 & 0 & 0 & 1 & 0 \\
\hline D16-0400 & 0 & 0 & 0 & 0 & 0 & 1 & 0 & 0 & 0 & 0 & 0 & 0 & 0 & 0 & 0 & 0 & 0 & 0 & 0 \\
\hline D16-0325 & 0 & 0 & 0 & 0 & 0 & 0 & 0 & 0 & 0 & 0 & 0 & 0 & 1 & 0 & 0 & 0 & 0 & 0 & 0 \\
\hline D19-0475 & 0 & 1 & 0 & 0 & 1 & 0 & --- & 1 & 1 & 0 & 1 & 0 & 0 & 0 & 1 & 1 & 1 & 0 & 1 \\
\hline D20-0775 & 1 & 1 & 1 & 0 & 1 & 1 & 1 & 1 & 1 & 1 & 1 & 1 & 0 & 1 & 1 & 1 & 1 & 1 & 1 \\
\hline D20-1100 & 0 & 0 & 0 & 0 & 0 & 0 & 0 & 0 & 0 & 0 & 0 & 0 & 0 & 0 & 0 & 0 & 1 & 0 & 0 \\
\hline D20-1000 & 0 & 1 & 1 & 0 & 0 & 0 & 0 & 0 & 1 & 1 & 0 & 1 & 1 & 0 & 0 & 0 & 0 & 0 & 0 \\
\hline E01-0850 & 1 & 1 & 0 & 1 & 1 & 1 & 0 & 1 & 1 & 1 & 1 & 1 & 1 & 1 & 1 & 1 & 1 & 1 & 1 \\
\hline E01-0450 & 1 & 1 & 1 & 1 & 1 & 1 & 1 & 0 & 1 & 1 & 1 & 1 & 1 & 1 & 0 & 1 & 1 & 1 & 1 \\
\hline E05-1075 & --- & 1 & 0 & 0 & 1 & 0 & 0 & 1 & 1 & --- & 0 & 0 & 0 & 0 & 1 & 1 & 0 & 1 & 1 \\
\hline E05-0600 & --- & 0 & 0 & 0 & 0 & 0 & 0 & 0 & 0 & --- & 0 & 0 & 0 & 0 & 0 & 0 & 0 & 0 & 0 \\
\hline E11-1675 & 1 & 1 & 1 & 1 & 1 & 1 & 0 & 1 & 1 & 1 & 1 & 1 & 1 & 1 & 1 & 1 & 1 & 1 & 1 \\
\hline E14-0850 & 0 & 0 & 0 & 0 & 0 & 0 & 1 & 1 & 0 & 0 & 1 & 0 & 1 & 1 & 1 & 0 & 1 & 0 & 1 \\
\hline E15-0700 & 1 & 1 & 0 & 1 & 1 & 1 & 1 & 1 & 1 & 1 & 1 & 1 & 0 & 0 & 0 & 1 & 0 & 1 & 1 \\
\hline E16-0550 & 0 & 0 & 0 & 0 & 0 & 1 & 0 & 0 & 0 & 0 & 0 & 0 & 0 & 0 & 0 & 0 & 0 & 0 & 0 \\
\hline E16-1175 & 1 & 0 & 1 & 1 & 1 & 1 & 0 & 1 & 0 & --- & 1 & 1 & 1 & 0 & 0 & 1 & 0 & 0 & 0 \\
\hline E16-1050 & 0 & 0 & 0 & 0 & 0 & 0 & 0 & 0 & 0 & 1 & 0 & 0 & 1 & 0 & 0 & 0 & 0 & 1 & 0 \\
\hline E16-1025 & 0 & 1 & 0 & 0 & 1 & 0 & 0 & 1 & 0 & 1 & 1 & 0 & 0 & 1 & 0 & 1 & 1 & 0 & 1 \\
\hline E17-0900 & 0 & 1 & 0 & 0 & 1 & 0 & 0 & 1 & 1 & 1 & 0 & 0 & 0 & 0 & 1 & 1 & 1 & 0 & 1 \\
\hline Mean & & & & & & & & & & & & & & & & & & & \\
\hline
\end{tabular}

${ }^{\mathrm{z}}$ Cultivar or selection numbers correspond to those in Table 1 . 
Cultivar and advanced selection ${ }^{2}$

\begin{tabular}{|c|c|c|c|c|c|c|c|c|c|c|c|c|c|c|c|c|c|c|c|}
\hline 1 & 1 & 1 & 0 & 0 & 0 & 0 & 0 & 1 & 1 & 1 & 0 & 0 & 0 & 0 & 0 & 0 & 0 & 0.40 & 0.59 \\
\hline 1 & 1 & 1 & 1 & 0 & 1 & 1 & 0 & 0 & 1 & 1 & 0 & 1 & 0 & 0 & 1 & 1 & 0 & 0.49 & 0.68 \\
\hline 1 & 1 & 0 & 0 & 0 & 0 & 0 & 0 & 0 & 1 & 0 & 0 & 1 & 0 & 0 & 0 & 0 & 0 & 0.18 & 0.32 \\
\hline
\end{tabular}

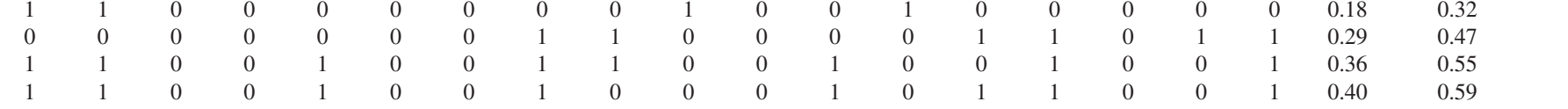

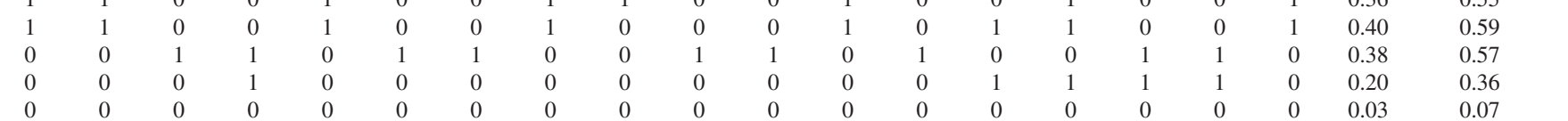

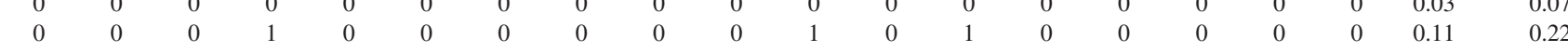

$\begin{array}{lllllllllllllllllllllll}0 & 0 & 0 & 0 & 0 & 0 & 0 & 0 & 0 & 0 & 0 & 0 & 1 & 1 & 1 & 0 & 0 & 1 & 0.18 & 0.32 \\ 1 & 1 & 0 & 1 & 0 & 1 & 1 & 1 & 1 & 1 & 0 & 1 & 1 & 1 & 0 & 0 & 0 & 1 & 0.45 & 0.64\end{array}$

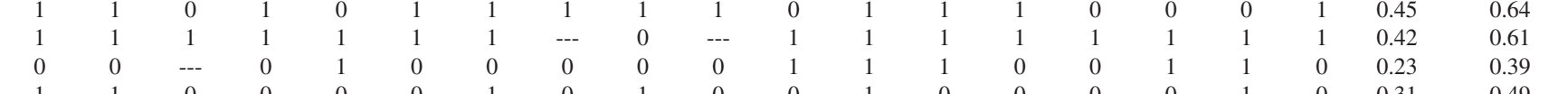

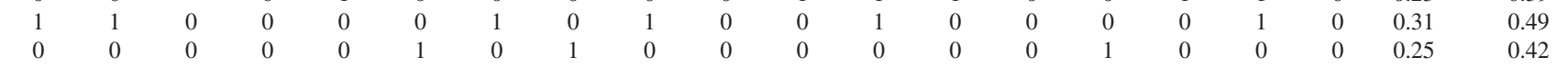

$\begin{array}{llllllllllllllllllllll}1 & 1 & 1 & 0 & 0 & 0 & 0 & 1 & 0 & 0 & 0 & 0 & 0 & 0 & 0 & 0 & 0 & 0 & 0.27 & 0.44\end{array}$

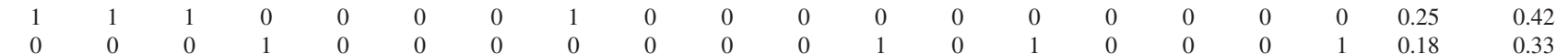

$\begin{array}{llllllllllllllllllll}0 & 0 & 0 & 0 & 0 & 0 & 0 & 0 & 1 & 0 & 0 & 0 & 0 & 1 & 0 & 0 & 0 & 1 & 0.18 & 0.33\end{array}$

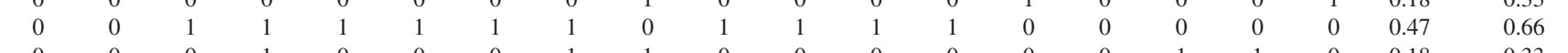

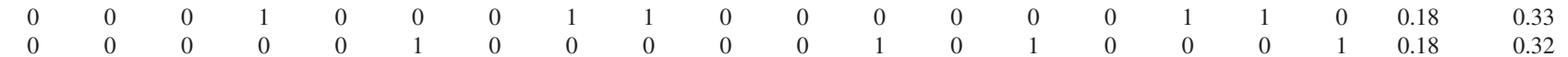

$\begin{array}{lllllllllllllllllllllll}0 & 0 & 1 & 1 & 0 & 1 & 1 & 1 & 1 & 1 & 1 & 0 & 1 & 1 & 1 & 1 & 1 & 1 & 0.50 & 0.69 & 1 \\ 1 & 1 & 0 & 1 & 1 & 0 & 1 & 1 & 1 & 1 & 1 & 0 & 1 & 1 & 0 & 1 & 1 & 1 & 0.48 & 0.67\end{array}$

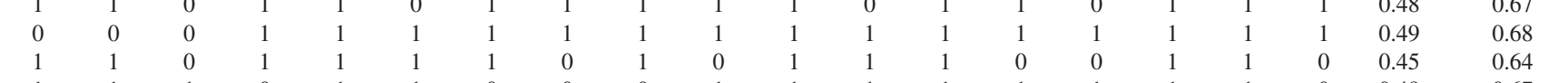

$\begin{array}{lllllllllllllllllllllll}1 & 1 & 1 & 0 & 1 & 1 & 0 & 0 & 0 & 1 & 1 & 1 & 1 & 1 & 1 & 1 & 1 & 0 & 0.48 & 0.67\end{array}$

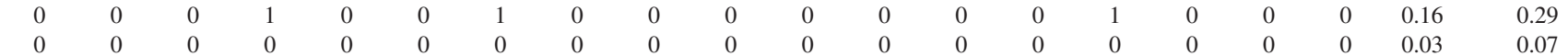

$\begin{array}{llllllllllllllllllllllllll}0 & 0 & 0 & 0 & 0 & 0 & 0 & 0 & 0 & 0 & 0 & 0 & 0 & 0 & 0 & 0 & 0 & 0 & 0.03 & 0.08\end{array}$

$\begin{array}{lllllllllllllllllllllllll}0 & 0 & 0 & 0 & 0 & 0 & 0 & 0 & 0 & 0 & 0 & 0 & 0 & 0 & 0 & 0 & 0 & 0 & 0.06 & 0.13\end{array}$

$\begin{array}{llllllllllllllllllllll}0 & 0 & 0 & 0 & 0 & 1 & 0 & 1 & 0 & 1 & 0 & 0 & 1 & 0 & 0 & 0 & 1 & 0 & 0.23 & 0.39 & 0.47\end{array}$

$\begin{array}{llllllllllllllllllll}1 & 1 & --- & 0 & 1 & 1 & 1 & 1 & 1 & 1 & 1 & 1 & 1 & 1 & 1 & 1 & 0 & 0 & 0.47 & 0.67 \\ 1 & 1 & 1 & 0 & 0 & 0 & 0 & --- & 1 & 1 & 1 & 1 & 1 & 0 & 1 & 1 & 1 & 1 & 0.47 & 0.66\end{array}$

$\begin{array}{lllllllllllllllllllll}0 & 0 & 0 & 0 & 0 & 0 & 0 & 0 & 0 & 0 & 0 & 0 & 0 & 0 & 0 & 1 & 1 & 0 & 0.05 & 0.13\end{array}$

$\begin{array}{llllllllllllllllllllllll}0 & 0 & 0 & 0 & 0 & 0 & 0 & 0 & 0 & 0 & 1 & 0 & 1 & 1 & 0 & 0 & 0 & 1 & 0.11 & 0.22\end{array}$

$\begin{array}{lllllllllllllllllllllllll}0 & 0 & 0 & 0 & 0 & 0 & 0 & 0 & 0 & 0 & 0 & 0 & 0 & 0 & 0 & 0 & 0 & 0 & 0.03 & 0.07\end{array}$

$\begin{array}{lllllllllllllllllllllll}0 & 0 & 1 & 1 & 0 & 1 & 1 & 1 & 1 & 1 & 1 & 0 & 1 & 1 & 1 & 1 & 1 & 1 & 0.50 & 0.69 \\ 1 & 1 & 1 & 1 & 1 & 1 & 1 & 1 & 1 & 1 & 0 & 0 & 0 & 1 & 1 & 1 & 1 & 1 & 0.48 & 0.67\end{array}$

$\begin{array}{lllllllllllllllllllllllll}1 & 1 & 1 & 1 & 1 & 1 & 1 & 1 & 1 & 1 & 1 & 1 & 1 & 1 & 1 & 0 & 0 & 1 & 0.36 & 0.55\end{array}$

$\begin{array}{lllllllllllllllllllll} & 1 & 1 & 1 & 1 & 1 & 1 & 1 & 1 & 1 & 0 & 1 & 1 & 1 & 1 & 1 & 0 & 0.48 & 0.67 \\ 1 & 1 & 1 & 1 & 0 & 0 & 1 & 0 & 1 & 0 & 1 & 0 & 1 & 1 & 0 & 1 & 1 & 1 & 0.43 & 0.62\end{array}$

$\begin{array}{lllllllllllllllllllllll}1 & 1 & 0 & 0 & 0 & 0 & 0 & 0 & 1 & 0 & 0 & 0 & 0 & 1 & 0 & 0 & 0 & 1 & 0.23 & 0.39\end{array}$

$\begin{array}{lllllllllllllllllllllllll}1 & 1 & 1 & 1 & 1 & 1 & 1 & 1 & 1 & 1 & 1 & 0 & 1 & 1 & 1 & 1 & 1 & 1 & 0.44 & 0.63 \\ 0 & 0 & 1 & 1 & 1 & 1 & 1 & 1 & 1 & 1 & 0 & 1 & 0 & 1 & 1 & 1 & 1\end{array}$

$\begin{array}{lllllllllllllllllllll}0 & 0 & 0 & 0 & 0 & 0 & 0 & 0 & 1 & 0 & 0 & 0 & 0 & 0 & 0 & 0 & 0 & 0 & 0.03 & 0.07\end{array}$

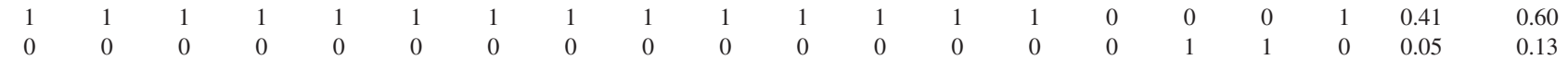

$\begin{array}{lllllllllllllllllllllll}0 & 0 & 0 & 0 & 0 & 0 & 0 & 0 & 0 & 0 & 0 & 0 & 0 & 0 & 0 & 0 & 0 & 0 & 0.05 & 0.13\end{array}$

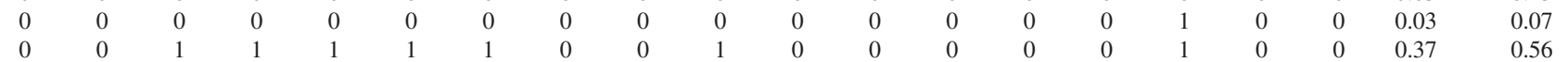

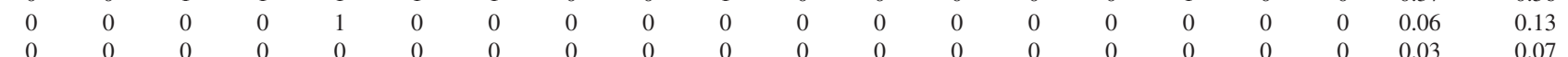

$\begin{array}{llllllllllllllllllll}0 & 0 & 0 & 0 & 0 & 0 & 1 & 0 & 0 & 0 & 0 & 0 & 0 & 1 & 0 & 0 & 0 & 1 & 0.11 & 0.22\end{array}$

$\begin{array}{llllllllllllllllllll}1 & 1 & 0 & 0 & 0 & 0 & 0 & 0 & 0 & 1 & 0 & 0 & 0 & 0 & -- & 0 & 0 & 0 & 0.31 & 0.49\end{array}$

$\begin{array}{llllllllllllllllllllll}1 & 1 & 0 & 0 & 1 & 1 & 1 & 1 & 0 & 1 & 1 & 0 & 1 & 0 & 1 & 0 & 0 & 0 & 0.50 & 0.69\end{array}$

$\begin{array}{llllllllllllllllllllll}0 & 0 & 0 & 0 & 0 & 0 & 1 & 0 & 0 & 0 & 0 & 0 & 0 & 1 & 0 & 0 & 0 & 1 & 0.11 & 0.22\end{array}$

$\begin{array}{lllllllllllllllllllllll}1 & 1 & 0 & 0 & 1 & 0 & 1 & 1 & 1 & 1 & 1 & 0 & 1 & 1 & 1 & 0 & 0 & 1 & 0.41 & 0.60 \\ 1 & 1 & 0 & 0 & 0 & 0 & 0 & 1 & 1 & 1 & 1 & 1 & 1 & 1 & 1 & 1 & 1 & 1 & 0.49 & 0.69\end{array}$

$\begin{array}{llllllllllllllllllllllll}1 & 1 & 1 & 1 & 1 & 1 & 1 & 1 & 1 & 1 & 1 & 1 & 1 & 1 & 1 & 1 & 1 & 1 & 0.36 & 0.54\end{array}$

$\begin{array}{lllllllllllllllllllll}1 & 1 & 0 & 0 & 0 & 0 & 0 & 0 & 0 & 0 & 0 & 0 & 0 & 0 & 0 & 0 & 0 & 0 & 0.26 & 0.43 \\ 0 & 0 & 0 & 0 & 0 & 0 & 0 & 0 & 0 & 0 & 0 & 0 & 1 & 0 & 0 & 0 & 0 & 0 & 0.03 & 0.08\end{array}$

$\begin{array}{llllllllllllllllllllllll}1 & 1 & 1 & 0 & 1 & 1 & 0 & 1 & 0 & 1 & 0 & 1 & 0 & 1 & 0 & 0 & 0 & 1 & 0.50 & 0.69 \\ 1 & 1 & 0 & 1 & 1 & 0 & 1 & 0 & 1 & 1 & 1 & 0 & 1 & 1 & 1\end{array}$

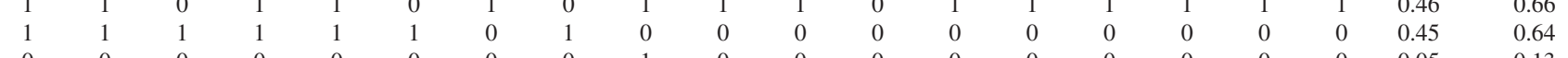

$\begin{array}{llllllllllllllllllllll}0 & 0 & 0 & 0 & 0 & 0 & 0 & 0 & 1 & 0 & 0 & 0 & 0 & 0 & 0 & 0 & 0 & 0 & 0.05 & 0.13\end{array}$

$\begin{array}{lllllllllllllllllllllll}--- & 1 & 1 & 1 & 1 & 0 & 1 & 0 & 0 & 0 & 1 & 1 & 1 & 0 & 1 & 0 & 0 & 1 & 0.45 & 0.65\end{array}$

$\begin{array}{lllllllllllllllllllllll}1 & 1 & 0 & 0 & 0 & 0 & 0 & 0 & 1 & 0 & 0 & 0 & 0 & 0 & 0 & 1 & 1 & 0 & 0.20 & 0.36\end{array}$

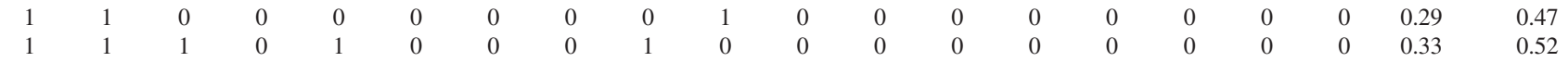

$\begin{array}{lll}0.28 & 0.44\end{array}$ 
Table 3. Genetic similarity of Dice's coefficient ${ }^{\mathrm{Z}}$ among 37 pawpaw cultivars or selections evaluated by RAPD markers.

\begin{tabular}{|c|c|c|c|c|c|c|c|c|c|c|c|c|c|c|c|c|}
\hline $\begin{array}{l}\text { Cultivar } \\
\text { or selection }\end{array}$ & 1 & 2 & 3 & 4 & 5 & 6 & 7 & 8 & 9 & 10 & 11 & 12 & 13 & 14 & 15 & 16 \\
\hline 1 PPF 1-7 Wye & 100.0 & & & & & & & & & & & & & & & \\
\hline 2 PPF 1-23 & 54.2 & 100.0 & & & & & & & & & & & & & & \\
\hline 3 PPF 2-54 & 65.1 & 62.2 & 100.0 & & & & & & & & & & & & & \\
\hline 4 PPF 8-58 & 47.8 & 63.8 & 60.0 & 100.0 & & & & & & & & & & & & \\
\hline $5 \quad$ PPF 9-47 & 41.0 & 50.0 & 44.4 & 56.4 & 100.0 & & & & & & & & & & & \\
\hline 6 PPF 9-58-2 & 63.0 & 53.6 & 62.7 & 56.6 & 62.0 & 100.0 & & & & & & & & & & \\
\hline 7 PPF 10-35 & 47.8 & 45.8 & 48.9 & 48.9 & 54.1 & 67.9 & 100.0 & & & & & & & & & \\
\hline 8 PPF 11-5 & 65.5 & 63.2 & 73.1 & 63.0 & 62.5 & 73.9 & 59.7 & 100.0 & & & & & & & & \\
\hline 9 PPF 11-13 (KSU) & 49.1 & 47.3 & 48.0 & 60.4 & 69.6 & 73.0 & 71.4 & 73.9 & 100.0 & & & & & & & \\
\hline 10 Middletown & 60.9 & 53.1 & 65.1 & 62.2 & 48.5 & 61.8 & 51.1 & 64.3 & 59.3 & 100.0 & & & & & & \\
\hline 11 Mitchell & 58.8 & 65.4 & 65.2 & 49.0 & 46.5 & 57.6 & 35.3 & 60.0 & 44.9 & 66.7 & 100.0 & & & & & \\
\hline $12 \mathrm{NC}-1$ & 60.0 & 69.4 & 60.9 & 50.0 & 57.1 & 51.7 & 60.0 & 67.8 & 63.2 & 62.5 & 60.4 & 100.0 & & & & \\
\hline 13 Overleese & 77.6 & 69.4 & 71.1 & 51.1 & 48.8 & 59.7 & 49.0 & 72.5 & 49.1 & 70.8 & 69.2 & 66.7 & 100.0 & & & \\
\hline 14 PA-Golden & 61.5 & 69.2 & 68.1 & 52.0 & 50.0 & 63.3 & 38.5 & 65.6 & 54.2 & 62.8 & 80.0 & 66.7 & 71.7 & 100.0 & & \\
\hline 15 Sunflower & 68.2 & 50.0 & 42.9 & 28.6 & 44.4 & 49.1 & 49.0 & 55.6 & 53.9 & 46.6 & 45.8 & 63.9 & 56.6 & 49.0 & 100.0 & \\
\hline 16 Taylor & 54.6 & 65.5 & 57.2 & 53.9 & 50.0 & 57.2 & 51.0 & 59.4 & 54.0 & 48.2 & 58.6 & 56.1 & 57.1 & 64.4 & 53.9 & 100.0 \\
\hline 17 Taytwo & 58.3 & 77.6 & 62.2 & 56.5 & 46.2 & 53.6 & 53.1 & 63.2 & 50.9 & 50.0 & 53.9 & 62.8 & 56.0 & 60.4 & 52.2 & 67.9 \\
\hline 18 Wells (PPF) & 48.0 & 51.0 & 63.9 & 45.8 & 39.0 & 54.2 & 40.0 & 56.7 & 47.5 & 52.0 & 63.0 & 46.2 & 53.9 & 58.2 & 41.7 & 55.2 \\
\hline 19 Wilson & 50.0 & 63.0 & 54.2 & 57.2 & 45.5 & 62.3 & 52.8 & 51.6 & 56.7 & 45.3 & 53.6 & 50.9 & 44.4 & 59.7 & 56.0 & 86.7 \\
\hline 20 PPF 1-7 Keedysville & 58.2 & 67.9 & 62.7 & 66.7 & 70.8 & 65.6 & 57.1 & 86.2 & 71.9 & 69.1 & 57.6 & 65.5 & 70.2 & 60.0 & 45.3 & 60.3 \\
\hline 21 PPF 1-68 & 85.2 & 54.2 & 59.1 & 40.0 & 35.9 & 53.6 & 45.8 & 59.7 & 40.0 & 68.1 & 58.8 & 52.0 & 77.6 & 53.8 & 66.7 & 54.6 \\
\hline 22 PPF 2-10 & 52.0 & 57.7 & 51.1 & 52.0 & 69.8 & 66.7 & 69.2 & 75.4 & 78.0 & 62.8 & 54.6 & 70.4 & 60.4 & 53.6 & 57.1 & 50.9 \\
\hline 23 PPF 3-11 & 44.4 & 40.8 & 40.9 & 47.8 & 60.0 & 66.7 & 66.7 & 66.7 & 75.0 & 46.8 & 38.5 & 54.9 & 36.7 & 41.5 & 47.8 & 36.4 \\
\hline 24 PPF 3-21 & 51.1 & 49.0 & 46.5 & 55.3 & 73.2 & 70.2 & 66.7 & 70.2 & 85.7 & 63.9 & 46.2 & 64.0 & 53.1 & 56.7 & 48.9 & 50.9 \\
\hline 25 PPF 4-2 & 54.9 & 58.8 & 54.2 & 52.0 & 61.9 & 62.1 & 70.6 & 70.0 & 78.0 & 60.0 & 55.6 & 79.3 & 64.2 & 58.2 & 58.3 & 54.2 \\
\hline 26 PPF 5-5 & 61.8 & 61.8 & 61.2 & 67.9 & 63.8 & 66.7 & 58.2 & 78.1 & 74.2 & 70.4 & 62.1 & 71.4 & 67.7 & 64.4 & 54.9 & 64.5 \\
\hline 27 PPF 7-90 & 53.1 & 65.4 & 44.4 & 59.6 & 60.5 & 59.7 & 53.1 & 55.2 & 67.9 & 58.3 & 61.5 & 66.7 & 64.0 & 64.2 & 52.2 & 50.0 \\
\hline 28 PPF 8-20 & 61.2 & 52.0 & 47.9 & 46.8 & 40.0 & 62.1 & 48.0 & 50.9 & 56.2 & 57.1 & 64.2 & 50.0 & 54.9 & 70.4 & 55.4 & 56.2 \\
\hline 29 SAA-Zimmerman-1 & 64.0 & 52.0 & 60.9 & 55.4 & 45.0 & 64.4 & 51.0 & 60.0 & 58.7 & 65.4 & 66.7 & 64.2 & 61.6 & 72.7 & 54.2 & 58.7 \\
\hline 30 PPF 2-49 & 65.5 & 59.3 & 57.2 & 60.4 & 57.8 & 63.5 & 50.9 & 56.3 & 58.1 & 75.5 & 65.5 & 59.7 & 64.3 & 64.4 & 46.2 & 58.1 \\
\hline 31 Sweet Alice & 63.0 & 58.2 & 54.9 & 46.2 & 43.5 & 62.5 & 46.4 & 58.5 & 54.0 & 55.6 & 67.8 & 58.7 & 63.2 & 73.3 & 52.8 & 60.3 \\
\hline 32 Rebecca's Gold & 45.3 & 55.6 & 58.3 & 58.8 & 56.5 & 64.5 & 48.1 & 60.3 & 64.5 & 49.1 & 56.1 & 53.6 & 47.3 & 62.1 & 47.1 & 65.6 \\
\hline 33 PPF 9-58-1 & 66.7 & 51.9 & 61.3 & 61.6 & 63.6 & 79.4 & 50.9 & 75.0 & 69.8 & 64.2 & 62.1 & 59.7 & 64.3 & 74.6 & 53.9 & 58.1 \\
\hline 34 Prolific & 60.0 & 80.0 & 62.2 & 69.4 & 68.2 & 56.2 & 53.1 & 69.0 & 59.7 & 58.3 & 56.7 & 65.4 & 70.6 & 59.3 & 52.2 & 63.2 \\
\hline 35 SAA-Zimmerman-2 & 62.3 & 65.3 & 68.1 & 64.0 & 63.6 & 66.7 & 53.9 & 75.5 & 63.3 & 66.7 & 61.8 & 63.0 & 75.5 & 71.4 & 49.0 & 61.0 \\
\hline 36 PPF 11-13 (PPF) & 50.9 & 49.1 & 43.1 & 59.3 & 68.1 & 70.8 & 70.2 & 69.7 & 99.9 & 60.8 & 46.7 & 64.4 & 48.3 & 52.5 & 51.9 & 53.1 \\
\hline 37 Wells (original) & 51.1 & 49.0 & 63.7 & 46.8 & 41.0 & 52.6 & 44.9 & 58.6 & 48.3 & 59.6 & 68.0 & 54.9 & 60.0 & 64.2 & 44.4 & 58.2 \\
\hline
\end{tabular}

${ }^{\mathrm{z} C o n v e r t i n g ~ f a c t o r s ~ t o ~ p e r c e n t a g e ~ v a l u e s . ~}$

two samples, with a difference in 6 of 71 markers and genetic identity of 0.905 (Tables 2 and 3). It is possible that the 'Wells' propagated by PPF was not from the original tree. A clear difference in 15 of 71 markers was observed in the two sample entries of SAA-Zimmerman (Table 2). SAA-Zimmerman was selected as an open-pollinated seedling of the old cultivar Zimmerman in 1982 (Layne, 1997). The genetic identity of 0.727 between the two sample entries and the relationship revealed by the cluster analysis (Table 3; Fig. 1) suggests the possibility that they might be full-sib seedling selections from the same openpollinated family of the old cultivar Zimmerman.

Genetic diversity of the existing gene pool of cultivated pawpaws, as estimated by Nei's gene diversity (He), revealed a level of genetic diversity similar to that of wild pawpaw populations $(\mathrm{He}=0.28$ of the cultivated (Table 1$)$ vs. $\mathrm{He}=0.25$ of the wild; Huang et al., 2000). This agrees with the history of pawpaw domestication and recent cultivar development. Most cultivars and selections were selected from superior trees in the wild and propagated clonally by grafting or as seedlings from openpollinated superior trees in the wild (Peterson, 1991). The overall genetic composition of cultivated pawpaws has not been subjected to extensive selection and has remained similar to that observed in wild populations (Huang et al., 2000). Genetic similarities ranged from 0.286 between 'Sunflower' and PPF 858 to 0.889 between PPF 2-10 and PPF 4-2 (Table 3). The result supports the idea that cultivars selected over a wide geographical range possess wide genetic variation. This may be particularly evident for cultivars such as 'Sunflower' that was selected from Kansas, at the westernmost periphery of the native range. Nevertheless, the genetic diversity of the current gene pool of the cultivated pawpaws may need to be further enhanced for pawpaw commercialization because new genes may be helpful to overcome several major obstacles to commercial development including occasional poor fruit set, short shelf life, and fruit seediness. (Peterson, 1991). This will enhance the fundamental genetic base for future pawpaw improvement.

Genetic Relatedness. The genetic relatedness among the cultivars and advanced selections were examined by UPGMA cluster analysis, as presented in Fig. 1. This dendrogram is a representation of apparent genetic similarity and it is not a 


$\begin{array}{lllllllllllllllllllll}17 & 18 & 19 & 20 & 21 & 22 & 23 & 24 & 25 & 26 & 27 & 28 & 29 & 30 & 31 & 32 & 33 & 34 & 35 & 36 & 37\end{array}$

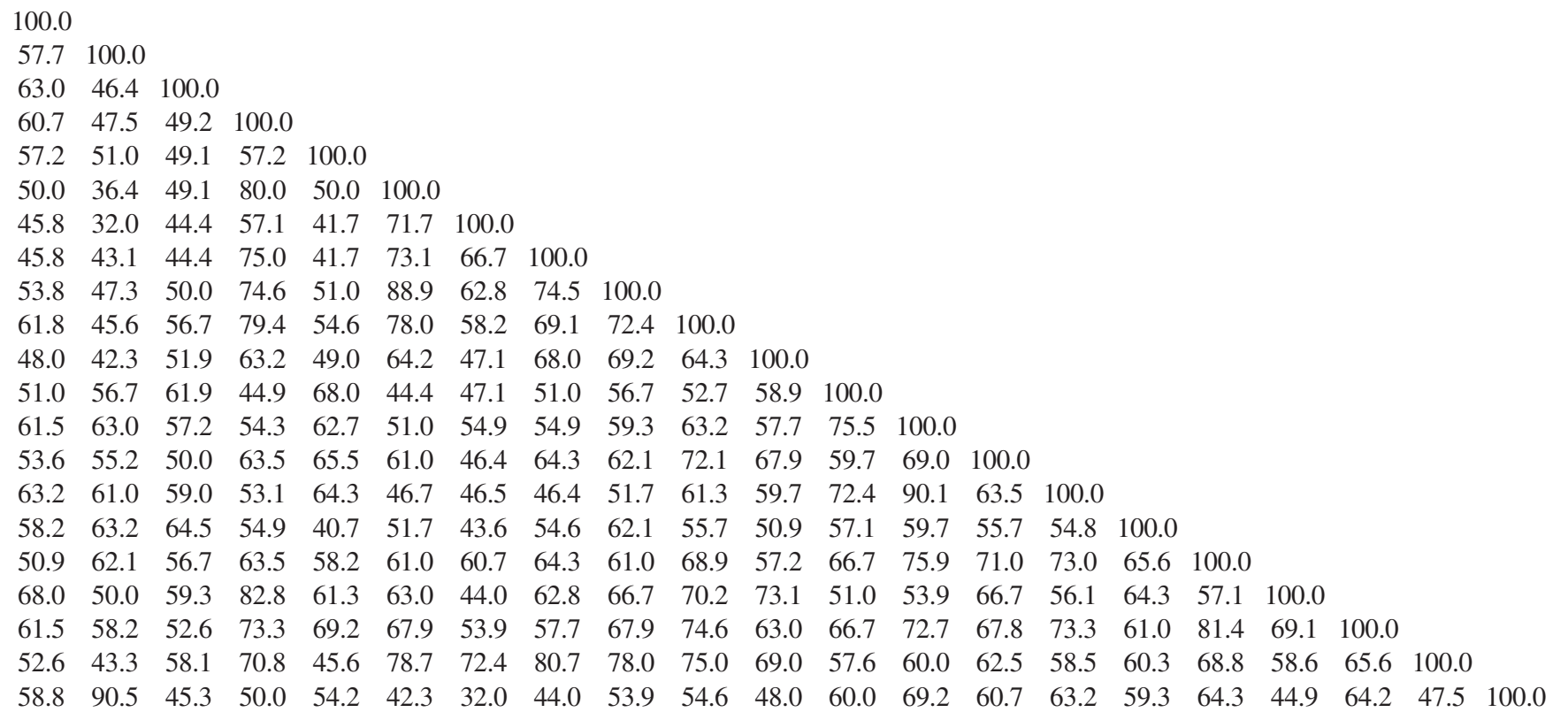

pedigree or family tree. The dendrogram, in general, separated the 34 cultivars and selections into two distinct clusters, the cluster of PPF (The PawPaw Foundation) selections from openpollinated seedlings at the historic collection of the Blandy Experimental Farm (BEF), Boyce, Va., and the cluster including the majority of extant cultivars selected from the wild and their derived selections. It also separated a distant out-group cultivar, Sunflower. This information is in agreement with the selection history and pedigree information, although that information is scarce and limited (Callaway, 1990; Layne, 1997; Peterson, 1991). Most PPF selections were selected from open-pollinated seedlings of superior pawpaw trees labeled as BEF accessions. The BEF accessions originated from the assembled germplasm collections from a national contest in 1916 and a 1917-50s multisource collection maintained at BEF (Anonymous, 1916; Peterson, 1991). Within this group, PPF 4-2, PPF 11-5 and PPF 11-13 are half siblings selected from the same parent tree labeled as BEF53. The half siblings of PPF 1-7 Keedysville/PPF 2-10 and PPF 9-47/PPF 10-35 were selected from BEF-30 and BEF-49, respectively. Others (PPF 3-11 from BEF-33, PPF 3-21 from BEF-43,
PPF 5-5 from BEF-54) were selected from a large nursery at the BEF. However, exceptions were observed regarding PPF 7-90 and NC-1 within this group. PPF 7-90 was recorded as an openpollinated seedling selection from RS-2, a pawpaw selection grown by Ray Schlaanstine $(\approx 1960)$ that descended from the Zimmerman collection, which itself was largely descended from the national pawpaw contest in 1916 (Anonymous, 1916). Therefore it is not surprising that PPF 7-90 might share similarities with BEF materials. NC-1 with recorded pedigree as 'Davis' $\mathbf{x}$ 'Overleese' (Layne, 1997) had not been in any doubt prior to a recent isozyme analysis (Huang, et al., 1997). The result in this present study confirms the isozyme result that $\mathrm{NC}-1$ was not closely related to 'Overleese'. This indicates that either the NC1 we sampled was not actually NC-1 or that NC-1 was not a progeny of 'Davis' $\mathrm{x}$ 'Overleese'. Doug Campbell originally selected NC-1 from hybrid seed he received from Corwin Davis ('Davis' female parent X 'Overleese' male parent, personal communication). However, recent conversations with Corwin Davis indicated that the pollen parent may or may not have been 'Overleese'. In the future, it would be ideal to collect NC-1, 


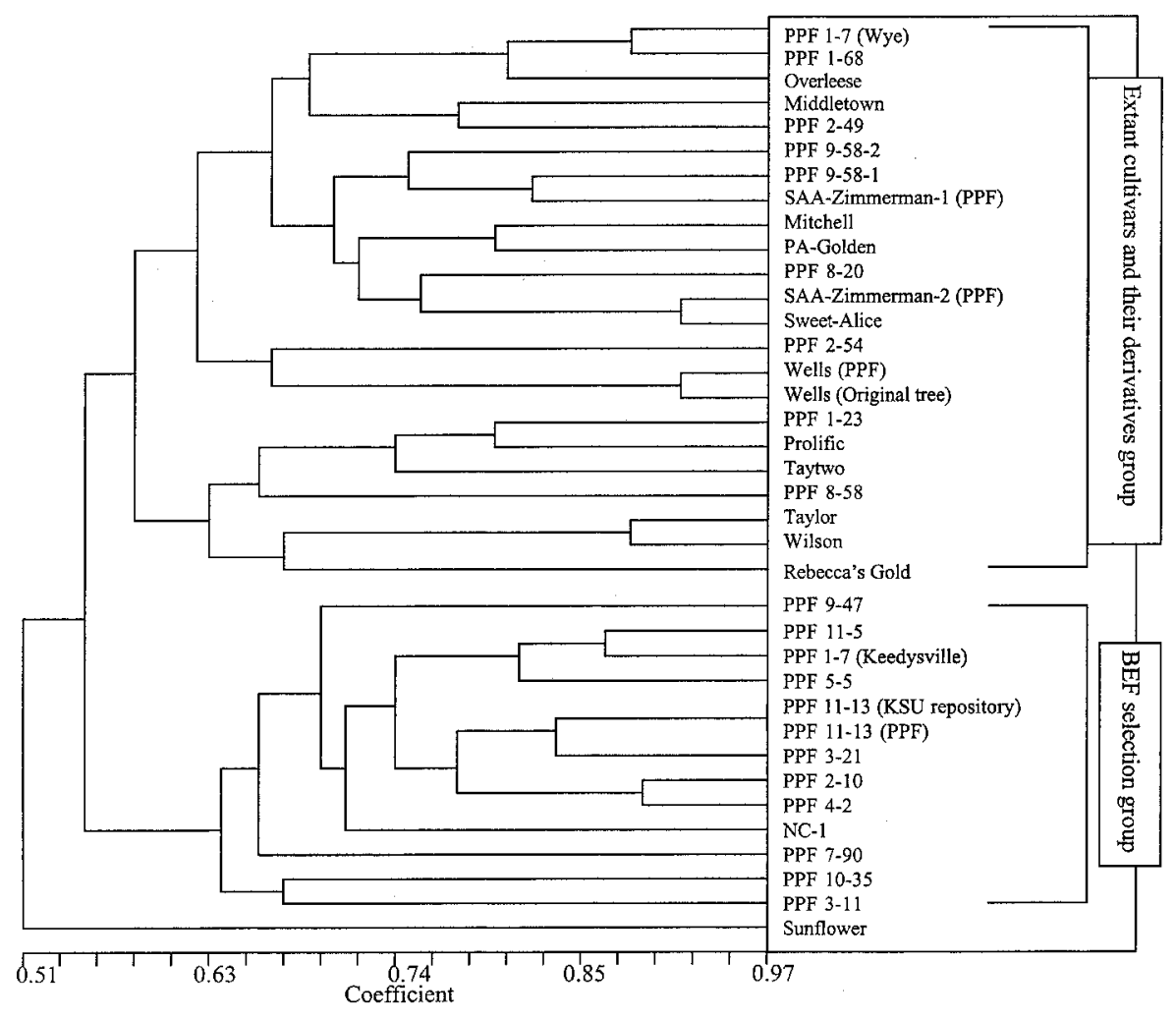

Fig. 1. RAPD markers-based UPGMA dendrogram of Dice coefficients of genetic similarity among 34 cultivars or selections of Asimina triloba.

'Davis' and 'Overleese' from original source trees if they exist and perform the analysis again.

The group of extant cultivars and their derivatives were revealed as a loosely grouped cluster with several distant subclusters, some showing possible parent-offspring relationships. For example, the subcluster of 'Overleese' and its offspring's PPF 1-7Wye and PPF 1-68 indicated a parentage relationship (Fig. 1). Similarly, the subcluster including 'Taytwo', PPF 1-23, 'Prolific' and PPF 8-58 revealed close genetic relationships. PPF 1-23 was recorded as an open-pollinated seedling from parent tree 'Taytwo' (Table 2). Corwin Davis selected 'Prolific' from a cultivated seedling (personal communication). The seeds may be derived either from the pollen parent or the female tree of 'Taytwo'. However, PPF 8-58 was not clustered with its halfsibling PPF 2-10 where both were derived from BEF-30. Furthermore, some subclusters may provide information on possible parentage relationships where no documented parentage records exist. The selection, PPF 2-49 was clustered with 'Middletown', suggesting PPF 2-49 was possibly derived from 'Middletown'. 'Sunflower' is distantly related to all groups noted. This was not observed in our isozyme study (Huang et al., 1997). One distinction of this cultivar is hobbyist reports that 'Sunflower' is selffruitful. Since almost all PPF selections resulted from a rescuing effort of collecting open-pollinated seeds from surviving trees in the historic germplasm sites (i.e., Buckman, Zimmerman, Blandy, Hershey, and Allard collections) it is possible that PPF 2-49 was derived from 'Middletown' (Table 2, Peterson, 1991). SAAZimmerman-2 was closely clustered with 'Sweet-Alice' with more than $90 \%$ genetic identity suggesting a possible mislabeling of SAA-Zimmerman-2 with 'Sweet-Alice'. It is worth noting that the relationship between 'Mitchell' and 'PA-Golden' revealed in the dendrogram is in agreement with our previous isozyme study.
In fact, RAPD markers provided a clear separation of these two cultivars that were not previously distinguishable due to the paucity of isozyme markers. On the other hand, the UPGMA dendrogram using the genetically defined RAPD markers did reveal some relationship differences that were not found using isozyme markers. The genetically defined RAPD markers actually provided improved resolution and a more logical explanation of relationships among currently extant cultivars and advanced selections over the isozyme analysis.

In conclusion, the consensus fingerprint profiling using the RAPD markers is a useful and reliable method for establishing genetic identities of pawpaw cultivars and advanced selections. It also provided an improved discrimination for evaluating genetic diversity and relatedness in comparison with the isozyme markers. Although actual pedigree information is best for determining genetic relationships, in the case of pawpaw, where pedigree information is scarce or nonexistent, RAPD profile data as presented in this study are valuable. The RAPD markers, when genetically defined and properly used (Huang et al., 2000; Lynch and Milligan, 1994), should provide a useful reference for germplasm curators who must make decisions regarding sampling strategies and managing germplasm repositories and for breeders who are constantly facing decisions of selecting parents for breeding programs and eliminating offspring in the early stages of evaluation.

\section{Literature Cited}

Anonymous. 1916. Where are the best papaws? J. Hered. 7:291-296.

Ausubel, F.M., R. Brent, R.E. Kingston, D.D. Moore, J.G. Seidman, J.A. Smith, and K. Stuhl. 1987. Current protocols in molecular biology. Wiley, New York.

Callaway, M.B. 1990. The pawpaw (Asimina triloba). Ky. State Univ. Publ. No. CRS-Hort1-901T.

Damman, A.J. 1986. Effects of seasonal changes in leaf quality and abundance of natural enemies of the insect herbivores of pawpaws. $\mathrm{PhD}$ diss. Cornell Univ., Ithaca, N.Y.

Darrow, G.M. 1975. Minor temperate fruits, p. 276-277. In: J. Janick and J.N. Moore (eds.). Advances in fruit breeding. Purdue Univ. Press, West Lafayette, Ind.

Dice, L.R. 1945. Measures of the amount of ecological association between species. Ecology 26:297-302.

Flory, Jr., W.S. 1958. Species and hybrids of Asimina triloba in the northern Shenandoah Valley of Virginia. North. Nut Growers Assn. Annu. Rpt. 49:73-75.

Huang, H., D.R. Layne, and R.N. Peterson. 1997. Isozyme polymorphisms for identification and assessment of genetic variation in cultivated pawpaws [Asimina triloba (L.) Dunal]. J. Amer. Soc. Hort. Sci. 122:504-511.

Huang, H., D.R. Layne, and D.E. Riemenschneider. 1998. Allozyme variation and geographic differentiation in pawpaw [Asimina triloba (L.) Dunal]. J. Amer. Soc. Hort. Sci. 123(4):635-641.

Huang, H., D.R. Layne, and T.L. Kubisiak. 2000. RAPD inheritance and diversity in pawpaw (Asimina triloba). J. Amer. Soc. Hort. Sci. 125:454-459.

Johnson, H.A., J. Gordon, and J.L. McLaughlin. 1996. Monthly varia- 
tions in biological activity of Asimina triloba, p. 609-614. In: J. Janick (ed.). Progress in new crops. ASHS Press, Alexandria, Va.

Jones, S.C. and D.R. Layne. 1997. Cooking with pawpaws. Ky. State Univ. Pawpaw Ext. Bul.-001.

Jones, S.C., R.N. Peterson, T. Turner, K.W. Pomper, and D.R. Layne. 1998. Pawpaw planting guide: Cultivars and nursery sources. Ky. State Univ. Pawpaw Ext. Bul. 002.

Kral, R. 1960. A revision of Asimina and Deeringothamnus (Annonaceae). Brittonia 12:233-278.

Layne, D.R. 1996. The pawpaw [Asimina triloba (L.) Dunal]: A new fruit crop for Kentucky and the United States. HortScience 31:777784.

Layne, D.R. 1997. Pawpaw, p. 403-404. In: The Brooks and Olmo, Register of fruit \& nut varieties. ASHS Press, Alexandria, Va.

Lynch, M. and B.G. Milligan. 1994. Analysis of population genetic structure with RAPD Markers. Mol. Ecol. 3:91-99.

McLaughlin, J.L. 1997. Anticancer and pesticidal components of pawpaw (Asimina triloba). N. Nut Growers Assn. Annu. Rpt. 88:97-106.

Nei, M. 1973. Analysis of gene diversity in subdivided populations. Proc. Natl. Acad. Sci. USA 70:3321-3323.

Nei, M. and W.H. Li. 1979. Mathematical model for studying genetic variation in terms of restriction endonucleases. Proc. Natl. Acad. Sci. USA 76:5269-5273.

Peterson, R.N., J.P. Cherry, and J.G. Simmons. 1982. Composition of pawpaw (Asimina triloba) fruit. N. Nut Growers Assn. Annu. Rpt.
73:97-106

Peterson, R.N. 1986. Research on the pawpaw (Asimina triloba) at the University of Maryland. N. Nut Growers Assn. Ann. Rpt. 77:73-78.

Peterson, R.N. 1991. Pawpaw (Asimina). In: J.N. Moore and J.R. Ballington (eds.). Genetic resources of temperate fruit and nut crops. Acta Hort. 290:567-600.

Pickering, C. 1879. Chronological history of plants, p. 881. Little and Brown Co. Boston, Mass.

Pomper, K.W., D.R. Layne, and R.N. Peterson. 1999. The pawpaw regional variety trial, p. 353-357. In J. Janick (ed.). Perspectives on new crops and new uses. ASHS Press, Alexandria, Va.

Popenoe, W. 1917. The best pawpaws. J. Hered. 8:21-33.

Shannon C.E. and W. Weaver. 1949. The mathematical theory of communication. Univ. of Ill. Press, Urbana.

Wagner, D.B., G.R. Furnier, M.A. Saghai-Maroof, S.M. Williams, B.P. Dancik, and R.W. Allard. 1987. Chloroplast DNA polymorphisms in lodgepole and jack pines and their hybrids. Proc. Natl. Acad. Sci. USA 84:2097-2100.

Williams, J.G., A.R. Kubelik, K.J. Livak, J.A. Rafalski, and S.V. Tingey. 1990. DNA polymorphisms amplified by arbitrary primers are useful as genetic markers. Nucleic Acid. Res. 18:6531-6535.

White, C.A. 1906. The northern limit of the papaw tree. Science 23:749751.

Zimmerman, G.A. 1941. Hybrids of the American pawpaw. J. Hered. 32:83-91. 